\title{
The topographic relationship between the maxillary teeth roots and the maxillary sinus floor, assessed using panoramic radiographs
}

\author{
Anna Starzyńska $(\mathbb{D})$, Paulina Adamska $(\mathbb{D})$, kukasz Adamski
}

Department of Oral Surgery, Medical University of Gdańsk, Poland

\begin{abstract}
Introduction: The topographic relation between the maxillary teeth roots and the maxillary sinus floor is important for diagnosis and planning of many surgical procedures. The aim of the study was to assess the topographic relationship between posterior maxillary teeth and the sinus floor.

Materials and methods: 50 pantomographs of patients aged 18-72, treated at the Medical University of Gdańsk, were analysed. We analysed only maxillary molars and premolars. Teeth were assessed using Kwak classification. Statistical analysis was carried out using STATISTICA 13.3.

Results: We analysed 180 molars and 181 premolars (total 361). According to the root-sinus classification, most of the first molars were type V (55.96\%), most of the second molars - type III (32.29\%), most of the first premolars - type I (76.09\%) and most of the second premolars - type III (35.96\%). Non-parametric Spearman's rank-order correlation coefficient revealed significant correlation between right and left molars and between right and left premolars $(p<0.05)$.

Conclusions: Proper assessment of the pantomograph allows for correct pre-operative planning, which may affect the course of the procedure and enables to avoid possible complications. These findings may have clinical applications.

Keywords: Maxillary sinus / dental imaging / pantomographic radiographs
\end{abstract}

\section{Citation}

Starzyńska A, Adamska P, Adamski $Ł$. The topographic relationship between the maxillary teeth roots and the maxillary sinus floor assessed using panoramic radiographs. Eur J TransI Clin Med. 2018;1(2):31-35.

DOI: $10.31373 /$ ejtcm/102746

Corresponding author:

Anna Starzyńska, Department of Oral Surgery, Medical University of Gdańsk, Dębinki 7, 80-211, Gdansk, Poland

e-mail: anna.starzynska@gumed.edu.pl

No external funds.

Available online: www.ejtcm.gumed.edu.pl

Copyright ${ }^{\circledR}$ Medical University of Gdańsk

This is Open Access article distributed under the terms of the Creative Commons Attribution-ShareAlike 4.0 International. 


\section{Introduction}

The maxillary sinus (antrum of Highmore) is the largest of paranasal sinuses. It is the first of the sinuses to develop and is present at birth. It is pyramid-shaped and is comprised of four walls: nasal (base), posterior, anterior and floor of the orbit (roof) [1-2]. The sinus communicates with the nose through an opening into the semilunar hiatus. An additional hiatus is sometimes present [2-3]. This sinus has seven recesses: zygomatic (in the zygomatic bone), alveolar (in the alveolar process of maxilla), orbital process, infraorbital, lacrimal, palatal and a recess formed after tooth extraction [34]. The relation of maxillary teeth roots to the maxillary sinus floor is important for diagnosis and planning of many surgical procedures, e.g. extraction, dental or orthodontic implant placement or sinus lift $[2,5-6]$.

The aim of this study was to assess the pantomographic images and to evaluate topographic relationship of the posterior maxillary teeth to the maxillary sinus floor.

\section{Materials and methods}

Fifty pantomographic radiographs of patients aged 18-72, treated at the Department of Oral Surgery of the Medical University of Gdańsk (Poland), were analysed. Inclusion criteria: presences of at least one first or second permanent molar in maxilla, fully erupted posterior teeth, complete development of the maxillary sinus and not damaged by any disease, fully developed root apices without resorptions, pantomograph of good quality. Patients were generally healthy, not suffering from chronic diseases, not taking any medications and antibiotics. We analysed first molars, second molars, first premolars and second premolars, because the roots of these teeth are in the closest to the sinus floor. Exclusion criteria were: lack of one first or one second molar in the maxilla, not fully erupted teeth, not fully developed maxillary sinus, root apices with resorption, bad quality of pantomograph, chronic diseases, taking medications. Patients' full anonymity was preserved during this study.

Teeth were identified using the Fédération Dentaire Internationale (FDI) classification. Radiological examinations were assessed by two independent researchers and then critically evaluated by the third author.

Teeth were assessed using Kwak et al. classification (root-sinus classification; Figure 1). This classification is based on the root-sinus relationship:
- type I - the roots of the posterior tooth are not in contact with inferior wall of the sinus;

type II - the root apex/apices is/are located in contact with maxillary sinus floor;

- type III - the buccal root apex/apices is/are observed over inferior wall of the sinus;

- type IV - the palatal root apex is located over maxillary sinus floor;

- type $\mathrm{V}$ - the buccal and palatal apices are observed over inferior wall of the sinus [7].

Statistical analysis was carried out using STATISTICA 13.3 (StatSoft Inc. Tulsa, United States) licensed by the Gdańsk Medical University. Normal distribution of variables characterizing objects was verified using the Shapiro-Wilk test. Non-parametric Spearman's rank correlation coefficient was used. $P$ value of $\leq 0.05$ was considered statistically significant.

\section{Results}

We analysed 180 permanent molars and 181 premolars (total 361 teeth): 44 right first molars, $48 \mathrm{sec}$ ond molars, 40 left first molars and 48 left second molars in the maxilla; 46 right first premolars, 43 second premolars, 46 left first premolars and 46 left second premolars in the maxilla.

According to the root-sinus classification, most of the first molars were type $\mathrm{V}(47 ; 55.96 \%)$, the second molars were type III $(31 ; 32.29 \%)$, the first premolars were type I (70; 76.09\%) and the second premolars were type III (32; 35.96\%) (Table 1). Non-parametric Spearman's rank-order correlation coefficient revealed statistically significant correlation between right and left first molars $(p=0.030)$, second molars $(p<0.010)$, first premolars $(p<0.010)$ and second premolars $(p=0.003)$.

\section{Discussion}

The root apices of the molars are generally located closer to the maxillary sinus floor than the premolar apices. The evaluation of radiographs is very important in dental treatment. Endodontic treatment of teeth with root apices above the inferior wall of the sinus (types III, IV and V) can contribute to the perforation of the mucous membrane. Dentists should be careful when extracting teeth, because an oroantral communication may arise in such cases. Removal of the teeth should be carried out atraumatically, with separation of roots [8-11]. 
A

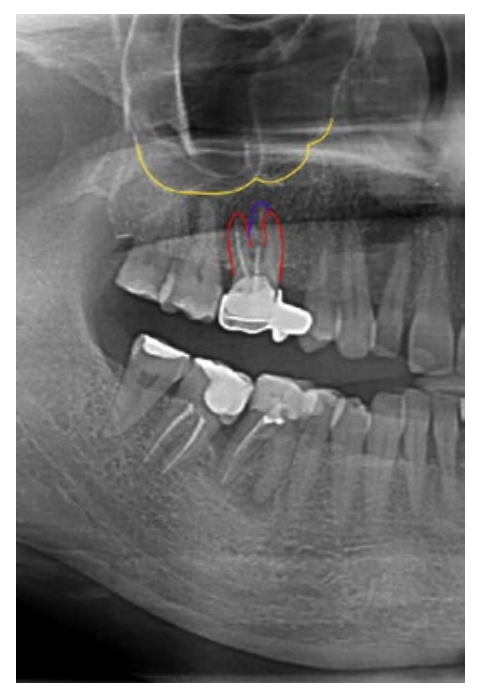

B

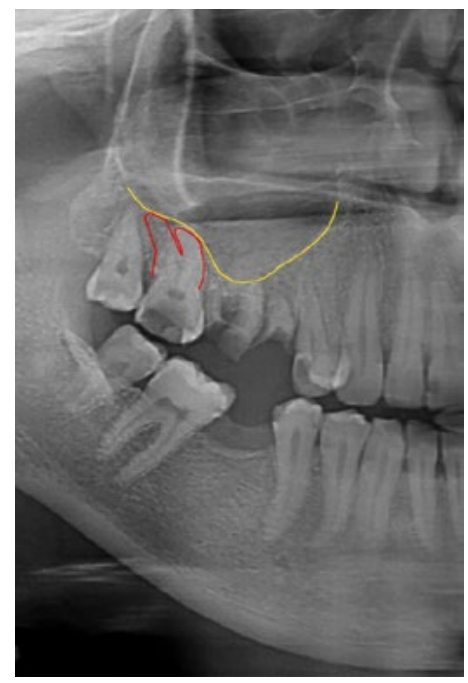

C

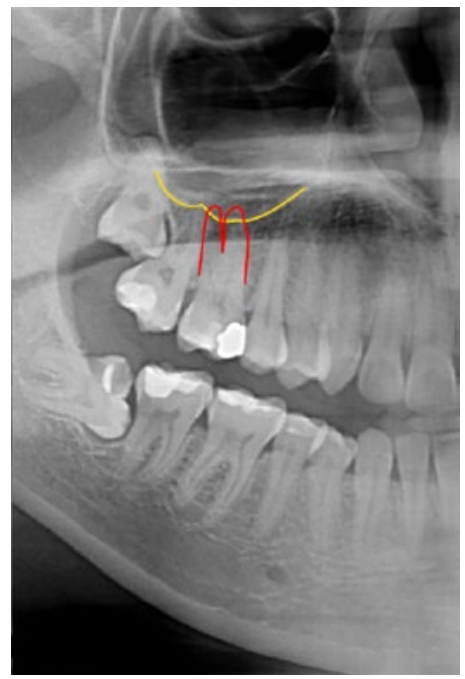

D

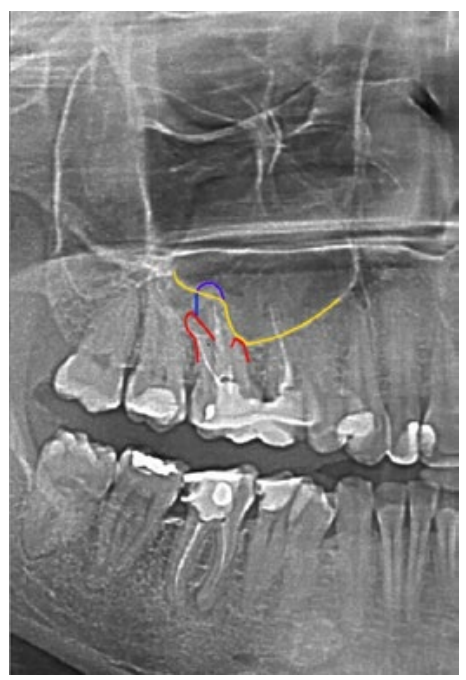

Panoramic radiograph is one of the most frequently used dental imaging. This imaging shows a $2 \mathrm{D}$ view of maxilla and mandible. It is helpful in the assessment of teeth and bone. Sometimes ghost images form in the pantomographs, which results in the image being unclear and inaccurate. Panoramic radiography is relatively safe as the radiation dose is very low [12-13].

The relationship between tooth root apices and sinus floor plays a vital role in periodontal surgery. Huang et al. and Brunsvold et al. described that maxillary sinusitis resulted from periodontal treatment of
$\mathbf{E}$

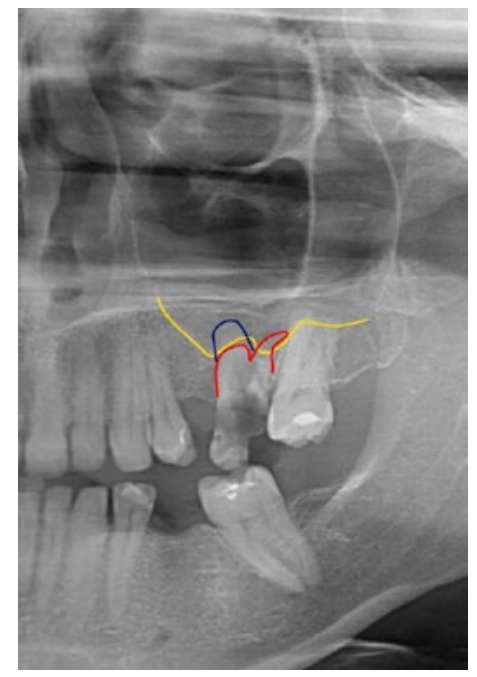

the first permanent molars having deep periodontal and bony pockets [14-16]. Fry et al. and Shokri et al. described that most of the first premolars are not in contact with inferior wall of the sinus. In our study the results were the same $[10,16]$. The most common type observed in the first molars was the one with the buccal and palatal apices over the floor of the sinus. Shokri et al. assessed teeth on cone beam computed tomography. The difference between left and right side was not statistically significant in Fryet al. study, but in our study it proved significant $[10,16]$. 


\section{Conclusions}

Radiological examination should be routinely performed to assess the stomatognathic system against all treatments in this localisation. This study demonstrated various relationships between the root apices and the floor of the maxillary sinus. These findings may

have clinical applications. Proper assessment of the pantomographs allow for correct pre-operative planning, which may affect the course of the procedure, and enables to avoid avoid possible complications.

Table 1. The relationship between the maxillary posterior teeth and the sinus floor ( $N$ - number of teeth; type I - the roots of the posterior tooth are not in contact with inferior wall of the sinus; type II - the root apex/apices is/are located in contact with maxillary sinus floor; type III - the buccal root apex/apices is/are observed over inferior wall of the sinus; type IV - the palatal root apex is located over maxillary sinus floor; type $\mathrm{V}-$ the buccal and palatal apices are observed over inferior wall of the sinus)

\begin{tabular}{|c|c|c|c|c|c|c|c|c|c|c|c|}
\hline \multirow{3}{*}{$\begin{array}{l}\text { Tooth } \\
\text { number } \\
\text { accor- } \\
\text { ding to } \\
\text { FDI clas- } \\
\text { sification }\end{array}$} & \multicolumn{10}{|c|}{ Root-sinus classification } & \multirow{3}{*}{$\begin{array}{c}\mathbf{p} \\
\text { value }\end{array}$} \\
\hline & \multicolumn{2}{|c|}{ Type I } & \multicolumn{2}{|c|}{ Type II } & \multicolumn{2}{|c|}{ Type III } & \multicolumn{2}{|c|}{ Type IV } & \multicolumn{2}{|c|}{ Type V } & \\
\hline & $\mathbf{N}$ & $\%$ & $\mathbf{N}$ & $\%$ & $\mathbf{N}$ & $\%$ & $\mathbf{N}$ & $\%$ & $\mathbf{N}$ & $\%$ & \\
\hline 14 & 36 & 78.26 & 5 & 10.87 & 1 & 2.17 & 0 & 0 & 4 & 8.70 & \multirow{2}{*}{$<0.010$} \\
\hline 24 & 34 & 79.91 & 7 & 15.22 & 0 & 0 & 0 & 0 & 5 & 10.87 & \\
\hline 15 & 15 & 34.09 & 11 & 25 & 15 & 34.09 & 0 & 0 & 3 & 5.82 & \multirow[t]{2}{*}{0.030} \\
\hline 25 & 13 & 28.26 & 13 & 28.26 & 17 & 36.96 & 1 & 2.17 & 2 & 4.35 & \\
\hline 16 & 5 & 11.36 & 8 & 18.18 & 6 & 13.64 & 6 & 13.64 & 19 & 43.18 & \multirow{2}{*}{0.030} \\
\hline 26 & 2 & 5.13 & 1 & 2.56 & 5 & 12.82 & 3 & 7.69 & 28 & 71.79 & \\
\hline 17 & 8 & 16.67 & 12 & 25 & 17 & 35.42 & 1 & 2.08 & 10 & 20.83 & \multirow{2}{*}{$<0.010$} \\
\hline 27 & 2 & 4.17 & 14 & 29.17 & 14 & 29.17 & 1 & 2.08 & 17 & 35.42 & \\
\hline $\begin{array}{l}\text { Total } \\
\text { number } \\
\text { of teeth } \\
\text { (each } \\
\text { type) }\end{array}$ & \multicolumn{2}{|c|}{115} & \multicolumn{2}{|c|}{71} & \multicolumn{2}{|c|}{75} & \multicolumn{2}{|c|}{12} & \multicolumn{2}{|c|}{88} & - \\
\hline $\begin{array}{l}\text { Total } \\
\text { number } \\
\text { of teeth }\end{array}$ & \multicolumn{11}{|c|}{361} \\
\hline
\end{tabular}




\section{References}

1. Lozano-Carrascal N, Salomó-Coll O, Gehrke SA, Calvo-Guirado JL, Hernández-Alfaro F, Gargallo-Albiol J. Radiological evaluation of maxillary sinus anatomy: A cross-sectional study of 300 patients. Ann Anat. 2017;214:1-8.

2. Al-Salman WT, Almas K. Maxillary sinus and success of dental implants: an update. Gen Dent. 2015;63(4):47-54.

3. Łasiński W. Anatomia głowy dla stomatologów 6th ed. Warszawa: PZWL; 1993. 207-9 pp.

4. Navarro P de L, Machado Júnior AJ, Crespo AN. Evaluation of the lacrimal recess of the maxillary sinus: an anatomical study. Braz J Otorhinolaryngol. 2013;79(1):35-8.

5. Ok E, Güngör E, Çolak M, Altunsoy M, Nur BG, Aglarci OS. Evaluation of the relationship between the maxillary posterior teeth and the sinus floor using cone beam computed tomography. Surg Radiol Anat. 2014;35(9):907-14.

6. Hayek E, Nasseh I, Hadchiti W, Bouchard P, Moarbes M, Khawam G, Bechara B, Noujeim M. Location of posterosuperior alveolar artery and correlation with maxillary sinus anatomy. Int J Periodontics Restorative Dent. 2015;35(4):e60-5.

7. Kwak HH, Park HD, Yoom HR, Kong MK,. Koh KS, Kim: HJ. Topographic anatomy of the inferior wall of the maxillary sinus in Koreans. Int J Oral Maxillofac Surg. 2004;33(4):382-8.

8. Koch F, Breil P, Marroquin BB, Gawehn J, Kunkel M. Abscess of the orbit arising 48 hours after root canal treatment of a maxillary first molar. Int Endod J. 2006;39(8):657-64.

9. Oberli K, Bornstein MM, von Arx T. Periapical surgery and the maxillary sinus: radiographic parameters for clinical outcome. Oral Surg Oral Med Oral Pathol Oral Radiol Endod. 2007;103(6):848-53.

10. Shokri A, Lari S, Yousef F, Hashemi L. Assessment of the relationship between the maxillary sinus floor and maxillary posterior teeth roots using cone beam computed tomography. J Contemp Dent Pract. 2014;15(5):618-22.

11. Shakhawan MA, Falah AH, Kawa AM. The relation of maxillary posterior teeth roots to the maxillary sinus floor using panoramic and computed tomography imaging in a sample of Kurdish people. Tikrit J Dent Sci. 2012;1(2):81-88.

12. Roque-Torres GD, Ramirez-Sotelo LR, de Almeida SM, Ambrosano GMB, Boscolo FN. 2D and 3D imaging of the relationship between maxillary sinus and posterior teeth. Braz J Oral Sci. 2015;14(2):141-8.

13. Gu Y, Sun C, Wu D, Zhu Q, Leng D, Zhou Y. Evaluation of the relationship between maxillary posterior teeth and the maxillary sinus floor using cone-beam computed tomography. BMC Oral Health. 2018;18(1):164.

14. Huang $\mathrm{CH}$, Brunsvold MA. Maxillary sinusitis and periapical abscess following periodontal therapy: A case report using three dimensional evaluation. J Periodontol. 2006;77(1):129-34.

15. Brüllmann DD, Schmidtmann I, Hornstein S, Schulze RK. Correlation of cone beam computed tomography (CBCT) findings in the maxillary sinus with dental diagnoses: A retrospective cross sectional study. Clin Oral Investig. 2012;16(4):1023-9.

16. Fry RR, Patidar DC, Goyal S, Malhotra A. Proximity of maxillary posterior teeth roots to maxillary sinus and adjacent structures using Denta scan ${ }^{\circledR}$. Indian J Dent. 2016;7(3):126-30. 